\title{
Introduction to the papers from the Faculty of Forestry and Environmental Management, University of New Brunswick
}

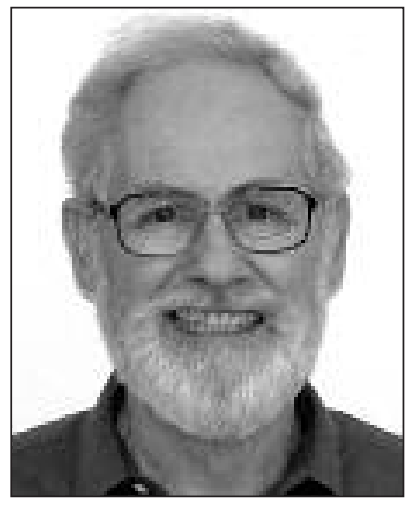

Graham R. Powell

Professor Emeritus, Faculty of Forestry and Environmental Management,

University of New Brunswick

Recipient of the 1999 CIF/IFC Canadian

Forestry Scientific Achievement Award. tions and the contributors be brought together in some sort of Faculty-related framework: hence this "introductory" paper.

The issue starts with two pieces: an editorial by the Dean of the Faculty, Dr. David MacLean, and an Of Relevance item by Professor Emeritus, the Reverend Dr. Norman Whitney, Order of Canada. The Dean writes of the current status and future directions of the Faculty. Norm Whitney, who in his eighties still teaches undergraduate courses (the fungal part of "Integrated Management of Insects and Fungi" and "Bioethics, Emotional Intelligence and the Nature of Spirituality"), takes on graduate students, and is active as a minister in the United Church of Canada, writes in "Together in the Forest" of the "spiritualness" of all parts of the ecosystems with which we deal, and the way those parts are connected with us.

Following this present introductory paper is a short piece that appeared in the student-produced publication in 1958 about the first 50 years of forestry instruction at UNB. It was written by then Senator G. Percy Burchill, who was a member of the first forestry class. The Dean referred to this article in his Editorial, and used the piece in January at the Kick-off Event for the Celebrations of this Centennial Year. Here, it serves to start a series of papers dealing essentially with history. It is followed by a brief history of the Faculty by Prof. Glen Jordan and me. Glen was a member of the Class of 1971, went on to a MScF degree in 1973, and then started his time as a Faculty member. I started at UNB in 1960 as a graduate student and newcomer to Canada, obtained a MScF degree in 1961, started in that year as a Faculty member, obtained a PhD degree from the University of Edinburgh in 1971, but did all the work and research for it at UNB using trees in the UNB Woodlot, retired in 1995, taught for three more years on contract, and am still privileged to have office space in the Faculty and access to its facilities.

Next comes a history of Forest Management in New Brunswick, which shows a correlation with developments in the Faculty. This is by BScF graduate (2006) Nancy Holloway (in fact, developed from her undergraduate thesis), Burtt Smith, a long-time Provincial government employee and a member of the BScF Class of 1940, and Glen Jordan. Then, Prof. Mark Roberts, who came to the Faculty in 1983 to handle Forest Ecology, shows how teachings and research in forest ecology have developed along with changes in how forests are viewed.

We move next to ancient history with two strikingly different papers. Professor Rodney Savidge, who has taught and researched in tree physiology (particularly as related to the cambium) in the Faculty since 1985, ventures into the distant origins of wood through his interest in permineralized wood. Wood as a structural substance is then covered, from the distant past to the promise of the future by Prof. Ian Smith, who came to the Faculty in 1988, and is now a University Research Professor, and Monica Snow. Monica obtained a BscFE degree from UNB in 1976. She completed her PhD degree in 2006 under the supervision of Prof. Smith.

There follow some papers dealing with undergraduate course offerings, and in some of these, relationships with graduate studies and research. Associate Professor Van Lantz shows how forest outputs, other than those of fibre, can now be given value that can be incorporated into forest management decisions, and also how he and his graduate students are exploring these aspects further. Van is one of the newer faculty members (2000), and as an economist by training (BA, Carleton, MA, Dalhousie, PhD, Simon Fraser), has a joint appointment with UNB's Department of Economics. He teaches courses in environmental and forest economics. Then Prof. Tom Beckley, who describes himself as a forest sociologist (Master's and $\mathrm{PhD}$ degrees in sociology from the University of Wisconsin), writes engagingly of how he has handled incorporation of "social values" into his teaching in the undergraduate curriculum. Tom also came to the Faculty in 2000. Before that, he had seven years of experience with the Canadian Forest Service in Alberta and in Atlantic Canada.

Professor Brigitte Leblon, with Armand LaRocque, Glen Jordan, and María Luz Gil describe how most courses in the remote sensing and geographic information system (GIS) areas are available online, often in French and English, and sometimes in Spanish, and give examples for the handling of one of those courses. Brigitte (with an Agricultural Engineering degree from Leuven, Belgium and a PhD from Montpellier, France, and Research Assistant experience at the University of Sherbrooke) joined the Faculty in 1994 to teach and conduct research in remote sensing. Armand LaRoque is an Instructor in a number of courses. Glen's main area of expertise is in GIS and computer simulations, and it was he who first ventured into online course delivery. Maria Gil provides the Spanish connection, and is based at Universidad Santiago de Compostela. She is responsible for transposing and handling some UNB courses for Spanish-speaking clientele.

Next, Professors Evelyn Richards and Ted Robak write of how they have developed an integrated series of Forest Engi- 
neering (FE) courses in Forest Operations Planning and Operations Research. Evelyn has a background in mathematics (BA and MA from UNB) and industrial engineering $(\mathrm{PhD}$, Dalhousie) and worked on contract for UNB for several years before joining the Faculty in 1999 to teach operations research and management planning in the FE Programme. Currently, she directs the FE Programme. Ted graduated with a BScFE degree in 1975, worked with New Brunswick International Paper in Dalhousie, NB, and then returned to UNB as a Faculty member in 1979 . He subsequently earned an MBA at the University of Maine and founded FORCE/Robak Associates Ltd. in 1984 to facilitate transfer of results of academic research to industry. By this means he has worked on forestry problems in Thailand, India, and Spain.

In the next paper, Prof. Robak writes of some of his work in Spain. He explains how a sustainable forest management scheme has been developed for the district of Galicia. Professor Leblon with Post-Doctoral Fellow, Amine Merzouki and Dean Dave MacLean give a brief account of the changes in teaching in the photogrammetry/photo-interpretation field at $\mathrm{UNB}$ and then go on to describe recent achievements and research applications in remote sensing. The latter apply to work in assessment of pest activity, fuel moisture conditions in relation to fire, crop evaluations, and evaluation of logs to increase useful wood output.

Jeremy Rickards, who is an Honorary Research Professor after 20 years as a Faculty member, next writes of the human factor in forest operations. Jeremy was chair of the former FE Department for 10 years. He still teaches a course in human factors engineering and through the human productivity consultant company he founded in 1993 (Selby Associates Inc.) continues to be active in workplace health and safety research and consulting in ergonomics.

In recent years there has been a tremendous increase in research activity in the Faculty of Forestry and Environmental Management-to the extent that the Faculty now has a research ranking of 1 among faculties/departments within UNB. In the next paper, the Dean, Dr. Dave MacLean tries to unravel some of the mystery that cloaks "the research game" at universities, particularly as it relates to forestry. It is not an easy game to play, and it is useful for those outside the universities (as well as those within universities) to learn something of it, remembering that faculty members have three responsibilities: teaching (professing), service to the university and the community, and research.

From the forestry research game we move to some papers that provide more evidence (additional to that already shown in other papers) of the powers of research from the university setting. Professor Tony Diamond, who joined the Faculty in 1994, is Chair of the Atlantic Cooperative Wildlife Ecology Research Network (ACWERN) and has a joint appointment with the Department of Biology, writes of results of research in ecology of birds. This relates primarily to species of the forest environment, though his research is considerably broader. Then, Prof. Charles Bourque and PhD student Quazi Hassan write of projected impacts of climate change on tree species in Nova Scotia. Charles received an MScF degree from UNB in 1985, and a PhD in 1993, and started as a Faculty member in 1994. His area is forest hydrometeorology.

Also related to climate change are two other papers. The first of these is by Prof. Dan Quiring and five of his research collaborators. They show how distribution of one of our treedamaging insect species can be related in the Atlantic Provinces to temperature isotherms and plant hardiness zones. Dan, with a Master's degree from Simon Fraser University, and a PhD from Laval University, joined the Faculty in 1986 to handle forest entomology. Don Ostaff, a forest entomologist, received his PhD in 1995 under Dan's supervision, and is an Adjunct Professor. Lester Hartling and Dan Lavigne are also forest entomologists, Hartling with a Master's degree from the University of Toronto, and Lavigne with a $\mathrm{BScF}$ degree from UNB (1981). Keith Moore, a forest health technician, is a graduate of the Maritime Forest Ranger School, and Ian DeMerchant, a spatial data analyst, has a BScF degree from UNB (1992). The second paper by Prof. Marek Krasowski and Mike Lavigne deals with coarse- and fine-root masses of two tree species and how differences in the roots might affect capacity of the trees to respond to global warming. Marek, a native and graduate forester of Poland, joined the Faculty in 2000 after receiving Master's and $\mathrm{PhD}$ degrees from the University of Victoria, and work with the British Columbia Ministry of Forests. Mike Lavigne (BScF, UNB, 1976) is an Honorary Research Associate of the Faculty and works with the Canadian Forest Service at the Atlantic Forestry Centre.

Professor Paul Arp has built an active and productive research team based on, but not restricted to, forest soils. Paul came to UNB in 1975 to work as a Research Associate with then soils professor, Dr. Helmut Krause, and shortly after joined the Faculty. The paper from some of his team deals with high-resolution mapping of flow channels and wet areas as an aid to forest operations planning. Besides Paul, the authors are Paul Murphy, Jae Ogilvie, Mark Castonguay, Cheng-fu Zhang, and Prof. Fan-Rui Meng. Paul Murphy is a Post-Doctoral Fellow with expertise in geochemistry and geomorphology. Jae Ogilvie received his $\mathrm{BScF}$ from UNB in 2005 and is GIS project manager. Mark Castonguay is a forest soils and GIS research assistant and also an Instructor in soils. Cheng-fu Zhang obtained an MScF degree from UNB in 2005 and is a Research Associate. Fan-Rui obtained his PhD under Paul Arp's supervision in 1994, continued working in Paul's laboratory, joined the Faculty in 1997 and is Research Director of the Noranda/Avenor Forest Watershed Research Centre.

Master's student, Elizabeth McGarrigle, with Professors Evelyn Richards, John Kershaw and Thom Erdle, then show how management planning models are sensitive to yieldcurve inputs from yield curves having different bases. This is followed by a paper by Prof. Ying Hei Chui, Director of UNB's Wood Science and Technology Centre (WSTC), and some WSTC personnel: Meng Gong, Shaun Price and Felisa Chan. They give an outline of how UNB plays a significant role in research and innovation in wood products in Atlantic Canada. Professor Chui came to UNB in 1988 as a Postdoctoral Fellow to work with Prof. Ian Smith, then became scientist and subsequently senior scientist at WSTC, joined the Faculty as Asst. Prof. in 1993, and reached the rank of Professor in 1999. Meng Gong obtained his PhD in 2000 under Prof. Smith's supervision, and is a Research Associate. Shaun Price obtained his PhD (Biology - Mycology) in 2006 under Prof. Whitney's supervision, and is a Research Scientist. Felisa Chan is a Research Associate and has a PhD through the Aus- 
tralian Pulp and Paper Institute and an MScF degree in Wood Science and Technology from the University of the Philippines.

Finally, after this broad-ranging series of papers that show something of the breadth of interest and expertise of 19 of the current 29 members of the Faculty of Forestry and Environmental Management and three of its retired members, a return is made to the trees themselves, those organisms that make the forests, the well-being and usefulness of which, we attempt to manage. I think it is apparent that foresters need to know more about the trees than anybody else. My own particular interest in the trees themselves arose from comparisons between the European species with which I grew up and about which I first studied, and the many more species I encountered in New Brunswick; teaching, first silviculture, and along with it delving into the reproductive processes of key species; and then trying to convey to students the rigours of descriptive dendrology and silvics, and the intricacies of tree development and reproduction. The essence of how trees come to be the way they are, how they acquire through iterative processes their particular forms and architecture, and how one species or genus differs from another, relates to the buds they produce. Hence, the final paper in this series arises from some of what I have learnt about buds through my teaching and research at UNB. 